REVISTA CHILENA DE LITERATURA

Abril 2009, Número 74, 123 - 137

\title{
LA 'CONCIENCIA COMO ESCRIBA': UNA ESCENA DE ESCRITURA INTERIOR EN LA OBRA DE HILDEGARD DE BINGEN
}

\author{
Daniela Picón \\ Universidad de Chile \\ danielapicon@gmail.com
}

RESUMEN / ABSTRACT

La imagen del 'libro interior', en el que se inscriben íntimamente nuestros actos y pensamientos, ocupó un papel central en la concepción cristiana de la espiritualidad, especialmente durante la Edad Media. Tal como se relata en los textos apocalípticos de la Biblia, este registro único e individual será leído por Dios el Día del Juicio Final y según lo que en ellos se halle escrito, Él juzgará a los hombres. Este trabajo se centra en una metáfora presente en varios tratados y sermones medievales, la 'conciencia como escriba', y, puntualmente, en el modo en que la visionaria benedictina Hildegard de Bingen (1098-1179) explica el acontecer de esta reveladora escritura en su Liber Divinorum Operum, donde tanto la escritura como la lectura constituyen actividades directamente relacionadas con la vida espiritual de los individuos.

Palabras Clave: Hildegard de Bingen, escritura visionaria, escritura y memoria, lectura, libro interior.

Abstract: The image of the 'inner book' as a record of our actions and thoughts, has had a main role in the Christian conception of spirituality, especially during the Middle Ages. As the Apocalyptic texts of the Bible relate, this one and individual record will be read by God during the Last Judgment and, according to that writing, He will judge the mankind. This text is focused on a metaphor that is present in several medieval treatises and sermons, the 'conscience as scribe', and more precisely, on the way in which the Benedictine visionary Hildegard of Bingen (1098-1179) explains how this revealing writing takes place, in her Liber Divinorum Operum (Book of the Divine Works), where both writing and reading are activities directly related to the spiritual life of the individuals.

KEY WORDS: Hildegard of Bingen, visionary writing, memory and writing, reading, inner book. 
¿En cuánto tiempo podrá leerse un libro donde están escritas las vidas de cuantos hombres ha habido y hay? ¿Acaso ha de haber tantos ánge-

les como hombres para que cada uno oiga a su ángel recitar su vida?

San Agustín

Ciudad de Dios, 20-XIV

El estudio de un suceso específico, la escena de la escritura -el acto que constituye la génesis misma del autor y de su obra, el momento en que ambos surgen, a través del texto-resulta especialmente revelador cuando se trata de autores visionarios, de profetas que se concibieron a sí mismos como 'secretarios de la humanidad' ${ }^{1}$, que tras una disposición divina, debieron poner por escrito la palabra revelada, para el conocimiento de los hombres.

Dando cuenta de la importancia de este momento, dos de los representantes más influyentes y asombrosos de la tradición visionaria, Hildegard de Bingen (1098-1179) y William Blake (1757-1827) representaron y simbolizaron, tanto en texto como en imagen ${ }^{2}$, esta escena, cuyo análisis nos lleva a comprender, entre otras cosas, cómo es que la palabra escrita, en distintos soportes materiales (la tablilla de cera, el pergamino, el códice, la plancha de metal grabada) es imaginada metafóricamente, como vínculo de comunicación entre Dios y los hombres, y cómo es que el propio visionario concibe su participación en este proceso.

1 A este respecto, remito al estudio de W.J.T. Mitchell "Visible Language: Blake's Art of Writing", inserto en el libro del mismo autor, Picture Theory. 111-150.

2 Los manuscritos iluminados, en el caso de Hildegard, cuya elaboración, en opinión de algunos investigadores, supervisó ella misma p.e. Madeline Caviness, especialmente en sus artículos "To see, hear, and Know All at Once", en Voice of the Living Light. 110-124 y "Hildegard as Designer of the Illustrations to her Works" en Hildegard of Bingen: The Context of her Thought and Art. 29-63. En el caso de Blake, sus poemas grabados, que constituyen un verdadero 'arte compuesto' de palabra e imagen. Ver: W. J. T. Mitchell, Blake's Composite Art. A Study of the Illuminated Poetry. 


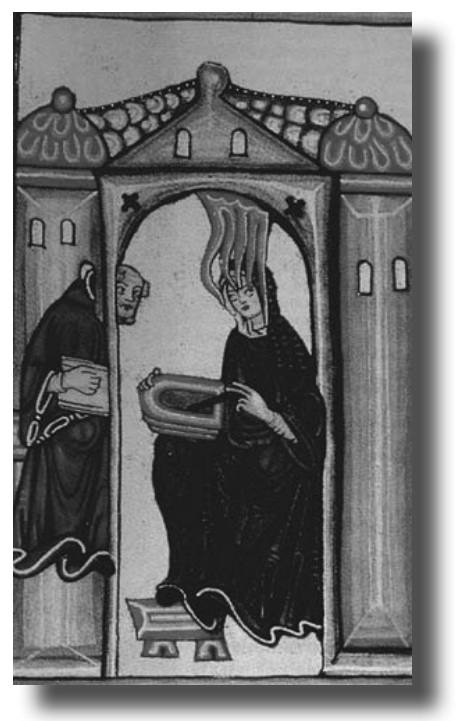

Fig. 1

Hildegard de Bingen representó la escena de la escritura en varios manuscritos de sus visiones. A este respecto podemos observar, por ejemplo, la imagen que se encuentra en el folio 1 del manuscrito facsimilar del Liber Scivias, hecho en Eibingen a comienzos del siglo XX, como copia del original del siglo XII, perdido durante la Segunda Guerra Mundial (Fig.1). En ella se la ve mirando al cielo, recibiendo la iluminación divina, con una tablilla de cera que sostiene en sus manos, en la que inscribe el mensaje con un estilo. En otras imágenes aparece acompañada por su secretario, Volmar, quien se asoma desde un espacio exterior al habitáculo en que ella se encuentra, y, mientras la mira directamente, escribe en un códice ${ }^{3}$.

Estas imágenes visuales presentes en los manuscritos, así como la correspondencia epistolar que la visionaria mantuvo con destacados personajes de su tiempo, y los prólogos de sus tres libros visionarios (Scivias, Liber Vitae

3 Una tercera variante de esta escena aparece en el manuscrito de Lucca, en la Primera Visión de la Parte Primera. Tras Hildegard, permanece de pie una mujer que se ha interpretado como Jutta, quien instruyó a la visionaria desde que era una niña, al momento de ingresar al convento de Disibodenberg. 
Meritorum y Liber Divinorum Operum) constituyen fuentes imprescindibles a la hora de interpretar la escena de la escritura de Hildegard. Este examen puede resumirse, fundamentalmente, en la auto-representación que realiza la profeta, en la cual la tablilla de cera que sostiene en sus manos, y en la que escribe, simboliza (según el pensamiento medieval, depositario de la tradición antigua) el libro interior de la memoria, en el que Dios inscribe en una primera instancia sus palabras, para que luego Hildegard dramatice ante su secretario, Volmar, esta escena original, quien pondrá por escrito esas palabras en el códice: el soporte exterior de la escritura interior, que se abre para la lectura del resto de los hombres.

No obstante, Hildegard también se refirió verbalmente -en una de las exégesis de sus visiones- al proceso de escritura y, particularmente, a la escritura que acontece en el interior. En la Cuarta Visión de su última gran obra visionaria, el Libro de las Obras Divinas ${ }^{4}$, fundamentalmente en el capítulo LXIII, la visionaria relata extensamente la actividad del libro interior de la memoria, y describe prolijamente de qué forma es que éste funciona, sirviéndose de algunas imágenes y metáforas propias de la tradición medieval. Este hallazgo, y su estudio, nos permitirá establecer un diálogo que amplía significativamente nuestro campo de análisis, por una parte, y al mismo tiempo, comprender más profundamente la concepción particular que esboza la visionaria en relación con la escena de la escritura en el 'libro interior' de los hombres.

La metáfora del libro interior de los individuos, en el que se escribe espiritualmente nuestra vida, ha sido estudiada a cabalidad por autores como Eric Jager y Mary Carruthers. Desde la Antigüedad, este libro interior, que contiene un registro de los pensamientos y acciones como soporte de nuestra conciencia y nuestra memoria, ha sido imaginado según las concepciones escriturarias que corresponden a cada época: la tablilla de piedra o cera, el rollo de pergamino, el códice y, en la actualidad tecnológica, como un disco duro que funciona en nuestra cabeza.

En el ámbito medieval temprano, el libro interior fue pensado fundamentalmente como una tablilla de cera, imagen atraída justamente desde

4 Todas las citas del Libro de las Obras Divinas corresponden a la edición en imprenta a cargo de María Isabel Flisfisch y María Eugenia Góngora. Asimismo, todos los énfasis son míos. 
la filosofía antigua ${ }^{5}$. Así como el acto de la escritura consiste en imprimir marcas, que son letras, sobre una superficie, la estructura de la memoria es imaginada como una tabla de cera, que se emplea para grabar y reunir las imágenes, como letras. El libro interior o libro del corazón se convirtió en símbolo de la experiencia religiosa personal y la vida espiritual interior, conteniendo un registro moral único e individual de la vida. Este registro interior podía ser leído íntimamente, para el conocimiento de uno mismo, pero también se mantiene, según la tradición bíblica, en el ámbito de la autoridad divina, para ser 'abierto' e interpretado por Dios, por ejemplo, el día del Juicio Final. Tanto en el libro de Daniel $(7,10)$ como en el Apocalipsis de Juan de Patmos $(20,12)$ la lectura de la escritura interior se encuentra capitalmente relacionada con el juicio divino. Esa escritura será la que en última instancia permita a Dios juzgar a los hombres: “(...) y fueron juzgados los muertos por las cosas que estaban escritas en los libros, según sus obras" (Apocalipsis 20, 12).

El propio San Agustín, cuya teología fue referente fundamental para la Edad Media y en especial para Hildegard, se refiere en varios pasajes de sus Confesiones, así como en La ciudad de Dios (20.14), al 'libro de la vida', o 'libro de la memoria', cuyo registro corresponde a la conciencia interior del hombre, libro que será leído e interpretado por Dios para el juicio de los hombres.

De este modo, varios autores dotaron de una especial significación -moral, sicológica- a los actos de inscribir, corregir y estudiar los libros, y tal como indica Jager, los autores medievales, en particular, continuaron con la tendencia patrística de alegorizar el examen y corrección de los manuscritos interiores en términos éticos, relacionados con la escritura de la interioridad moral.

Asimismo, en varios tratados medievales encontramos el tópico del 'escriba interior', o más precisamente, de la 'conciencia como escriba'. Un tratado anónimo, citado por Jager retrata al escriba interior, que copia en el libro todos los actos del hombre: "Donde quiera que vaya, mi conciencia

5 Tanto para Platón, especialmente en su Phaedrus, como para Aristóteles, De anima y De memoria et reminiscencia, las imágenes se encuentran impresas, copiadas en la memoria, como en el 'sello de un anillo'. 
no me abandona, sino que está siempre presente y escribe [scribit] todo lo que hago" (54).

Si el libro de la conciencia de los hombres está destinado a ser leído públicamente el día del Juicio Final, se hace necesario entonces que el escriba interior corrija cuidadosamente aquello que está escrito en el registro interior de los individuos, según lo cual todos seremos juzgados, con el propósito de enmendar los errores, para que así el libro interior se encuentre escrito conforme al 'libro de la vida', al libro ejemplar de la palabra de Dios. De este modo, el hombre está llamado a leer y examinar continuamente su propia autobiografía espiritual, para ser consciente de sus pecados, y así poder enmendar espiritualmente sus errores.

En la Cuarta Visión del Libro de las Obras Divinas, Hildegard se refiere a este proceso, mediante el cual la conciencia, o el alma, lee y escribe al mismo tiempo el libro interior de la espiritualidad del hombre. El alma es, por una parte, el soporte del cuerpo, el 'aliento de vida' otorgado por Dios al hombre, pero también es la que evalúa, discierne y regula todas las acciones que éste realiza. En el alma se encuentra la responsabilidad y el juicio, ella escribe y lee el libro interior de los hombres ${ }^{6}$.

Por una parte, el alma discierne las acciones del hombre a través de la escritura, convirtiéndose en la 'secretaria' de su conciencia: "De este mismo modo el alma discierne también en el pecho del hombre los pensamientos de cualquier origen, útil o inútil, considerándolos como si los escribiese y dispone cómo el hombre racional debe obrar según este mismo origen".

Escritura y discernimiento están íntimamente ligados y el alma-escriba le indica al hombre cómo es que debe actuar. Continúa Hildegard:

También el alma es esclava de los pensamientos, y los pensamientos son propios del alma, así como la tablilla en la cual se escribe; puesto que ella lima con esos pensamientos todas las obras del hombre y las prepara, como escribiéndolas (...) También ella misma, como

6 En otro pasaje "El alma está con el cuerpo, como el aire con la tierra y como el panal en medio de la miel". Hildegard compara el alma con un panal de abejas. Según Mary Carruthers (35-39), el panal de abejas constituye otro modelo de representación medieval de la memoria, ya que tal como las abejas van recolectando y organizando la miel en el panal, la información es almacenada ordenadamente en la memoria. Es interesante esto, además, porque como veremos más adelante, la escritura interior del alma se compara con el alimento: la 'dulce' miel. 
escribiendo, le vuelve a recordar con un triste sollozo las malas obras que el hombre ha cometido por los deleites de la carne; (...) y así el alma ofrece diligentemente al hombre que peca, el sollozo gracias al cual es salvado.

Como podemos ver, por una parte el alma escribe interiormente en la conciencia, estableciendo un juicio, pero al mismo tiempo 'lee' dicho registro, 'solloza' o 'murmura' al hombre sus pecados, hablándole interiormente, una vez que este se aleja del buen obrar, y se deja llevar por los 'deseos de la carne', alejando su libro interior del 'libro de la vida', compuesto por Dios. Más adelante leemos: "Por esto [el alma] mortifica al cuerpo con un suspiro doliente, mientra éste desprecia servir a Dios contra su voluntad (...) Por esto el deseo del alma le habla al hombre, que vive seguro en lo deleites de la carne, reprochándole así (...) ". El alma suspira y susurra al hombre sus pecados. El alma, dice Hildegard, permanece en el cuerpo 'a semejanza de los vientos -cuyo soplo no se ve, pero se oye'.

Debemos recordar aquí que el proceso de lectura medieval se concibió en el ámbito monástico como una experiencia mediante la cual el texto se incorpora -literalmente- en la memoria del lector. Según la espiritualidad monástica, la lectura es concebida como una ruminatio, una lectura lenta, hecha en profundidad, en voz baja, que se susurra y murmura, como las vacas rumian su alimento. Se trata de una lectura que se digiere, y constituye la base para la meditación y memorización de los textos. La palabra leída, rumiada, se concibe como 'alimento espiritual' y como la forma en que el texto penetra en nuestra memoria, a través del murmullo de la meditación.

Tal como afirma Mary Carruthers (164-65), el movimiento de la boca, que pronuncia las palabras, es el que dio origen a la ruminatio como una metáfora fundamental ligada a la actividad mnemotécnica. El verbo ruminare fue utilizado metafóricamente para significar la 'meditación', fase en la que el proceso de lectura se convierte justamente en una actividad ética. Si durante la lectio el individuo conoce la letra por medio de la gramática, la retórica, la historia y otras disciplinas útiles en una fase esencialmente informativa, no es sino durante la meditatio que el texto pasa a formar parte de nuestra propia interioridad, completando el proceso de lectura. "Ruminatio es una imagen de regurgitación, casi en el sentido literal; la memoria es como el 
estómago ${ }^{7}$, los textos almacenados son como dulces frutos extraídos del prado de los libros (o la lectura), y masticados en el paladar"'(Carruthers 164-65). Así, leemos en la Cuarta Visión del Libro de las Obras Divinas:

\begin{abstract}
"Y lo mismo que los alimentos, que primero son triturados por el molino de los dientes (...) De este mismo modo el alma rumia todas las obras del hombre y se las entrega a la memoria, de manera que no deje ninguna de ellas sin examinar; así como la comida es enviada al vientre a través de la garganta y así como la comida es triturada por los dientes, asi el alma escribe las obras del hombre discerniéndolas con su aliento; y reúne esta escritura por los pensamientos, para que el hombre conozca cuáles son sus obras, y para que él mismo las contemple continuamente como formas de las cosas en sus pensamientos, en los cuales se forman. Por consiguiente, el hombre no puede olvidarse de sus obras, porque son conservadas en sus pensamientos como las vísceras encerradas en el vientre".
\end{abstract}

Tanto la lectura como la escritura de la conciencia están ligadas en este pasaje -tan agustiniano- al acto de recordar al hombre sus obras, haciéndolo consciente de sus pecados, para que 'contemple' interiormente su libro ${ }^{8}$. Mary Carruthers comenta que las metáforas medievales basadas en actividades digestivas son tan poderosas que la digestión, como tal, puede considerarse como otro modelo funcional para las actividades complementarias de la lectura y memorización. En este sentido, la costumbre monástica de leer durante la comida es descrita en algunos textos en asociación explícita y literal con aquella metáfora que testifica que consumir libros es como consumir alimentos. Así lo indica una regla para mujeres adaptada de los escritos de San Jerónimo, donde la conexión es evidente: "Debe leerse durante la

7 De hecho, en el mismo estudio, Carruthers apunta que la concepción neurofisiológica de la memoria medieval, cuyas bases se encuentran ya en la filosofía antigua, fue considerada en tratados médicos compuestos con el fin de ayudar, mediante dietas especiales, a la memoria. De este modo, ciertos alimentos, como carnes y legumbres, fueron considerados como malas influencias para la actividad mnemotécnica, así como algunas hierbas eran consideradas especialmente buenas para el entrenamiento y práctica de la memoria.

8 Para un estudio de las nociones del pensamiento como un proceso visual, relacionado con otras metáforas y temas de la visualidad e invisibilidad, interioridad y exterioridad, ver un texto inédito de Ineke van 't Spijker: "Seeing with the Mind: Thinking as a visual process in the Twelfth Century". 
comida, porque mientras el cuerpo es satisfecho con alimento, la mente debe llenarse con la lectura" (Carruthers 167). A este respecto, el hombre, continúa Hildegard “(...) se deleita (...) en la sabiduría de las Sagradas Escrituras, con cuya dulzura es alimentado y confortado invisiblemente, así como el pez que ha sido reforzado por el aire y por el flujo de las aguas, vive a veces sin alimento en el agua", estableciendo - de paso- una clara alusión al ayuno, contrastando el alimento mundanal - del que puede prescindirse- con el sustento místico que otorgan las Escrituras.

La ruminatio del alma supone el discernimiento, el juicio de las obras del hombre, y es parte del alimento espiritual del que se nutre nuestra conciencia. "Pues el alma (...) misma [apunta Hildegard] lleva el alimento de las comidas y de las bebidas hacia el interior del hombre, para que su carne reviva (...) Por ello, el alma y la carne son una sola obra en dos naturalezas".

Según la tradición cristiana, la digestión de la palabra está íntimamente ligada a la inscripción en el interior de los individuos, en el libro individual de su memoria. La figura misma de Cristo está intrínsecamente relacionada con esta metáfora, ya que es en sí mismo la palabra de Dios encarnada, contenida en las Sagradas Escrituras, pero también es el cuerpo, la carne y la sangre, que alimenta espiritualmente a los fieles durante la celebración de la Eucaristía, celebración en que se posibilita la unión mística con Dios. Durante la Eucaristía, Dios se convierte en el alimento de los fieles. La comida es, por tanto, un símbolo poderoso. Por ello es que místicos y predicadores utilizaron la comida como metáfora de la gracia e inspiración, al momento de referirse a la unión con Dios 9 .

Por otra parte, el tópico popular medieval de la "Carta de Cristo" asemeja el cuerpo sufriente del Salvador con un documento escrito -su piel con un pergamino, sus heridas con las palabras, su sangre con la tinta. En este sentido, por ejemplo, es que el místico alemán Henry Suso evocó la promesa de Cristo de que la sabiduría "(...)debe leerse del libro abierto y herido de mi cuerpo crucificado" (Cit. en Jager 102).

Asimismo, dos son los momentos bíblicos en los que un libro le es entregado a los profetas para que ellos lo coman y luego profeticen la palabra de

$9 \quad$ Sobre la importancia de la comida en la espiritualidad medieval, en las prácticas religiosas y especialmente en el ámbito femenino, remito aquí al estudio de Caroline Walker Bynum, Holy Feast and Holy Fast. The religious Significance of Food to Medieval Women. 
Dios. Una vez que uno de los "seres vivientes" indica a Ezequiel (3:3) que deberá hablar las palabras de Dios a los rebeldes hijos de Israel, le dice:

\begin{abstract}
Mas tú, (...) oye como yo te hablo; no seas rebelde como la casa rebelde; abre tu boca, y come lo que yo te doy. Y miré, y he aquí una mano extendida hacia mí, y en ella había un rollo de libro. Y lo extendió delante de mí, y estaba escrito por delante y por detrás (...) Me dijo: Hijo de hombre, come lo que hallas; come este rollo, y vé y habla a la casa de Israel. Y abrí mi boca, y me hizo comer aquel rollo. Y me dijo: Hijo de hombre, alimenta tu vientre, y llena tus entrañas de este rollo que te doy. Y lo comí y fue en mi boca dulce como la miel. Luego me dijo: (...) vé y entra a la casa de Israel, y habla a ellos mis palabras.
\end{abstract}

Por otra parte, en el Libro del Apocalipsis, una vez que Juan se dispone a escribir el espectáculo de truenos y tormentas que constituyen las voces de los ángeles, la voz del cielo le indica que no debe escribir, sino comer el librito que uno de los ángeles sostiene abierto en sus manos, para que así luego profetice ante todos los pueblos y naciones: "Toma, y cómelo; y te amargará el vientre, pero en tu boca será dulce como la miel” (Ap. 10,9).

Esta imagen del profeta instruido a ‘comer el libro' de Dios está directamente relacionada con la recepción inmediata de la instrucción divina, del 'libro de la vida' que luego el profeta debe anunciar ante los infieles, aunque estos se nieguen a escucharlo. Por otra parte, el pasaje del libro de Dios que es digerido por los profetas fue comprendido según el modelo de lectura monástico, como metáfora del almacenamiento del libro del Señor en la memoria o corazón del individuo que lee. San Jerónimo, en su comentario al libro de Ezequiel afirma que "Cuando, mediante una meditación consciente, almacenamos el libro del Señor en el tesoro de nuestra memoria, nuestro vientre se llena espiritualmente, y nuestra barriga es satisfecha" (Cit. en Carruthers).

Así como el libro interior de la memoria o conciencia de los individuos se imaginó como una tablilla de cera en que sus obras y pensamientos son inscritos, al mismo tiempo la redención de las malas obras fue pensada como la posibilidad de suprimir ciertas acciones, borrándolas de nuestra memoria. La tablilla de cera fue utilizada durante la Edad Media como un soporte de escritura transitorio, de aquello que luego debía ser transcrito en un pergamino o códice, y del mismo modo, tal como señala Chartier, durante la Edad Moderna se utilizaron pequeñas 'libretas' cuyas páginas estaban recubiertas 
por un barniz, que permitía borrar en el momento lo escrito y reutilizar esa superficie para anotar en el momento ideas y pensamientos pasajeros, lo que asocia directamente la escritura, la memoria y el olvido "(...) como si toda inscripción pudiera o debiera ser borrada, como si siempre la escritura se esforzara por conjurar su propia fragilidad" (Chartier 16).

De este modo, la tablilla encerada, como soporte de escritura que permite escribir, pero al mismo tiempo borrar lo inscrito, para volver a escribir sobre ello ${ }^{10}$, como en una especie de palimpsesto, llevó a reflexionar sobre la conciencia como un texto que podía ser corregido, enmendado.

San Basilio (c. 329-379), por ejemplo, comparó el corazón del hombre con una tablilla de cera, que debía ser borrada, para que en ella pudiera inscribirse la nueva fe del converso (Jager 19), y tal como apunta Jager, en el ámbito religioso medieval se alegorizó frecuentemente esta imagen del libro interior examinado y corregido, especialmente en las glosas y comentarios a los pasajes proféticos de Daniel y Juan de Patmos, que ya hemos mencionado anteriormente, en los que se afirma que Dios, para juzgar a los hombres, abrirá y leerá los libros interiores que contienen el registro de la vida espiritual de cada uno de ellos.

Hemos visto ya de qué modo el alma escribe por una parte el libro de la conciencia de los hombres y, al mismo tiempo, lee para su contemplación interior el contenido de dicho registro. Claramente relacionada con la escritura en nuestra conciencia, como testimonio de la espiritualidad del sujeto, pero también con la posibilidad de corrección del libro de la conciencia, en la Cuarta Visión del Libro de las Obras Divinas encontramos la imagen de las vestiduras con las que el alma se atavía "(...) así como el cuerpo humano se viste con diversos tipos de vestiduras, así el alma se cubre con cada una de las obras de la carne, cualesquiera que sean, así como con vestiduras; éstas también aparecen continuamente en ella misma, visibles solo para otras almas y solo para los espíritus".

El alma inscribe en la memoria del individuo un registro de sus acciones y pensamientos y, al mismo tiempo, se atavía interiormente con las vestiduras de esas obras, sean buenas o malas. No obstante, los 'suspiros', los 'sollozos' del alma que se queja de los errores que el hombre inscribe en ella, la harán

10 Al respecto, ver el artículo de Jaques Derrida: "El trozo de cera de Freud y las tres analogías de la escritura". La escritura y la diferencia. 
derramar lágrimas, las que son interpretadas por Hildegard como la posibilidad de arrepentimiento que lleva a la redención del individuo.

A través de la penitencia, y con las lágrimas que el alma derrama doliente por los pecados del hombre, éste puede lavar las vestiduras con que ha vestido al alma, enjuagando sus vicios, e incluso puede cambiar dichas vestiduras, a través de abstinencias y oraciones y a través de la penitencia, adornando (...) su alma como con una túnica purpúrea; a través de ésta se ocultan las cicatrices de las heridas, de manera que nunca sean visibles en ella.

El libro de la conciencia del hombre, cuya lectura determinará su destino el día del Juicio Final, es escrito pero también leído por el alma, que 'susurra', 'rumia' su contenido interiormente. Al mismo tiempo, el alma que escribe y lee, se lamenta en sollozos, cuyas lágrimas posibilitan que el hombre enjuague sus errores, limpie sus vestiduras y enmiende así aquello que está inscrito en la autobiografía espiritual de su memoria.

A modo de epílogo, quisiera referirme muy brevemente a dos imágenes, dos dibujos de William Blake (1757-1827), el artista y visionario que estoy estudiando junto a Hildegard en el marco de mi tesis. Se trata de dos de las ilustraciones que Blake preparó para el poema de su compatriota contemporáneo Edward Young, Night Thoughts, publicado en Inglaterra, en pleno siglo XVIII, que están en plena consonancia con nuestro tema, porque en ellas, Blake concentra su énfasis justamente en la escena en que la conciencia registra las acciones del hombre a través de la escritura. 


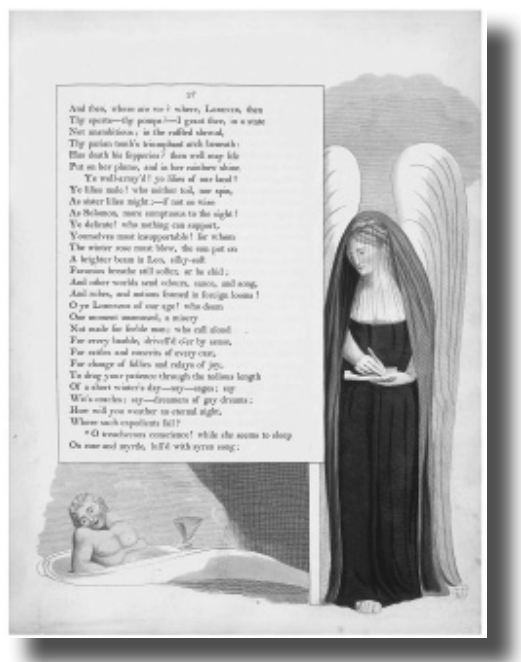

Fig. 2 Edward Young, Night Thoughts (17)

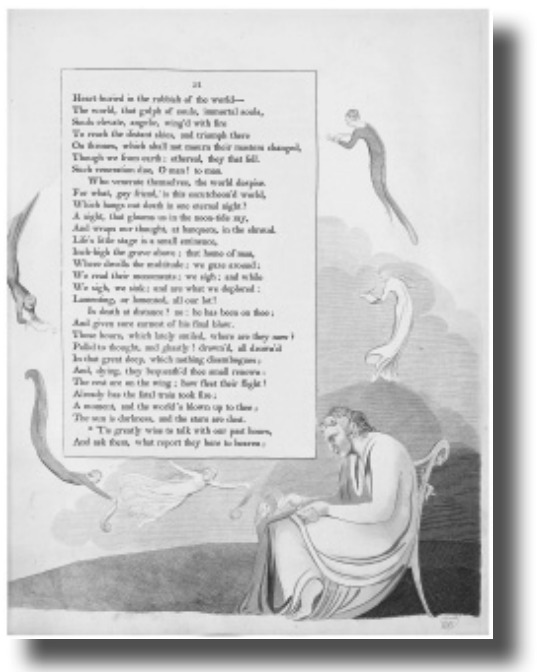

Fig.3 Edward Young, Night Thoughts (18)

En el poema, Young reflexiona a lo largo de nueve "noches" sobre la muerte y otros temas que de ella se derivan, como la fugacidad de la vida, el amor, la amistad y la debilidad humana. En el contexto del tratamiento de este último tema, la fragilidad del hombre, podemos observar en la figura 2 a la conciencia representada como un ángel cuyo rostro está cubierto con un velo. Mientras observa con congoja el estado de intemperancia de un sujeto borracho, la 'traicionera' conciencia registra y escribe el pecado en un libro que sostiene en sus manos.

La segunda ilustración (Fig.3), referente a la importancia de reflexionar retrospectivamente sobre nuestros actos, nos muestra a un 'buen hombre' que conversa con sus 'horas pasadas' y examina sus reportes. 


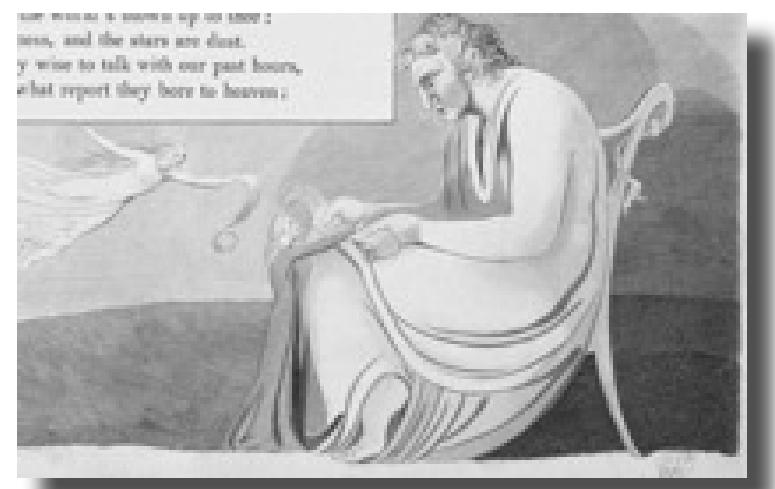

Fig.4 Edward Young, Night Thoughts (18) Detalle

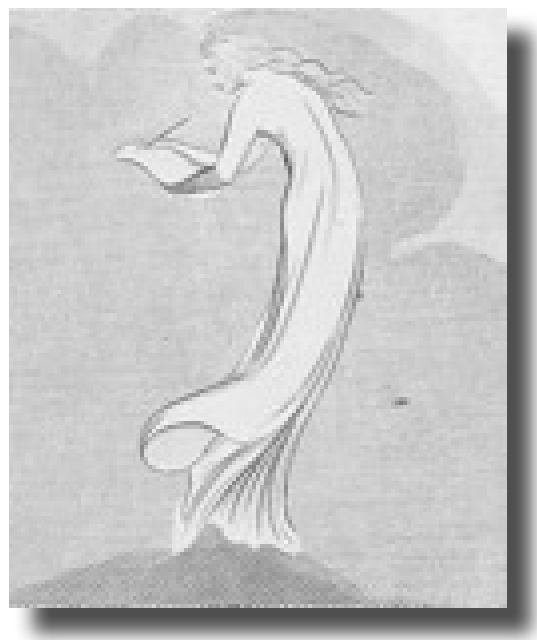

Fig.5 Edward Young, Night Thoughts (18) Detalle

Las horas han sido dibujadas por Blake como misteriosas hadas. Algunas descienden, para revelar al individuo los pergaminos en que han inscrito el registro de sus acciones, como podemos apreciar en el detalle (Fig.4). El hada, además, se enfrenta al hombre en una clara actitud de advertencia y precaución, tomando distancia, y anteponiendo la palma de su mano al lector.

Al mismo tiempo, otras horas llevan su registro al cielo, y mientras ascienden, como podemos ver en este segundo detalle (Fig. 5), continúan 
escribiendo: sobre sus propias vestiduras, cuyas mangas prolongadas se asemejan a un rollo de pergamino. La reflexión con que concluye el poema sentencia la importancia y lo prudente que es 'conversar con nuestras horas pasadas, e interrogarlas sobre el reporte que éstas llevan al cielo'.

La carga simbólica que en estas escenas visionarias se ha otorgado al gesto de la escritura y, en particular, la significación altamente espiritual que se confiere a la acción de transcribir interiormente en palabras, actos y pensamientos, se fundamenta y adquiere su sentido último en la lectura que de dicha materialidad escrita se supone: leer para rememorar, pero fundamentalmente, para imaginar.

\section{BIBLIOGRAFÍA}

Carruthers, Mary. The book of memory. A study of Memory in Medieval Culture. New York: Cambrige University Press, 1990.

Caviness, Madeline. “To see, hear, and Know All at Once”. Voice of the Living Light. Hildegard of Bingen and Her World. Ed. Barbara Newman. Berkeley and Los Angles: Universtity of California Press, 1998. 110-124.

"Hildegard as Designer of the Illustrations to her Works". Hildegard of Bingen: The Context of her Thought and Art. Ed. Charles Burnett y Peter Dronke. Londres: Warburg Institute, 1998. 29-63.

Chartier, Roger. Inscribir y borrar. Cultura escrita y literatura (Siglos XI-XVIII). Buenos Aires: Katz, 2006.

Derrida, Jaques. "El trozo de cera de Freud y las tres analogías de la escritura". La escritura y la diferencia. Barcelona: Anthropos, 1989. 271-317.

Hamesse, Jacqueline. "El modelo escolástico de la lectura". Historia de la lectura en el mundo occidental. G. Cavallo y R. Chartier, comp. Madrid: Taurus, 2001. 179-210.

Jager, Eric. The book of the heart. Chicago: University of Chicago Press, 2001.

Mitchell, W. J. T. "Visible Language: Blake's Art of Writing”. Picture Theory. Chicago: University of Chicago Press, 1994. 111-150.

Blake's Composite Art. A Study of the Illuminated Poetry. Princeton: Princeton University Press, 1978.

Sagrada Biblia. Madrid: Biblioteca de Autores Cristianos, 1960.

Van't Spijker, Ineke. "Seeing with the Mind: Thinking as a visual process in the Twelfth Century".

Von Bingen, Hildegard. Libro de las obras divinas. Trad. María Isabel Flisfisch. Barcelona: Herder (en prensa).

Walker Bynum, Caroline. Holy Feast and Holy Fast. The religious Significance of Food to Medieval Women. Berkeley: University of California Press, 1987. 